and total admissions in each month during the period October 1983 to January 1984 inclusive.

Returns showed that the most obvious change since the advent of the new Act was a 60 per cent reduction in admissions on the three-day order, formerly Section 29 now Section 4, plus a parallel and presumably related 40 per cent reduction in regrading in-patients to 28-day order status (formerly Section 25, now Section 2). There was a modest (approximately 15 per cent) increase in admissions on the 28-day order, but the diffierence may not be significant. Overall it seemed that total admissions had remained quite constant over the period under consideration, irrespective of which Mental Health Act was in force.

It seems reasonable to assume for this inquiry that, if respondents (42 per cent of the total) are typical of consultants throughout the West Midlands Region, then the introduction of the new Act has so far occasioned few problems and the future is faced with reasonable equanimity.
Although this paper has highlighted doubts and anxieties, those who share them are in the minority. But a note of caution is appropriate. As many respondents pointed out, though they had encountered no difficulties as yet, it had to be recognized that there had been little experience so far. The hospital returns show no striking change in the pattern of admissions nor in the use of the various orders, apart from acceleration of a trend apparent for some time of a reduction in the use of the three-day order. This is now presumably given emphasis by the exclusion of the Section 4 order from the consent to treatment provisions of the 1983 Act and the more stringent criteria which apply to this section.

\section{Acknowledgements}

I wish to express my sincere gratitude to the respondents for the trouble they took and their detailed and interesting replies. I am also grateful to hospital administrators and their medical records officer colleagues for the hospital returns.

\title{
A Need for Pastoral Counselling: Report of a Conference
}

Robin Skynner, Group-Analytic Practice, 88 Montagu Mansions, London W1

In November 1983, a Weekend Residential Conference was held at St George's House, Windsor Castle, on the theme 'The Bishop and his Family', to study the need for pastoral counselling, not only of the laity, but of the clergy also. The conference was chaired by the Right Reverend Michael Mann, Dean of Windsor, and attended by 15 Bishops of the Church of England, and their wives.

Mrs Leslie Rimmer, Deputy Director of the Family Policy Studies Centre, presented an outline of research on the present state of marriage and the family in Britain. Next I focused on some of the basic knowledge that the "helping professions' could offer towards pastoral care, the need for carers at all levels to have support available at times, and the value of peer-groups for this purpose. The Right Reverend Hewlett Thompson, Bishop of Willesden, described the three-tier pastoral support scheme operating in the London Diocese, which he has chaired for the London Bishops. The scheme has comprised a number of experienced group leaders seconded from their posts in the helping professions, who lead groups of selected volunteers, including both clergy and laity. When the numbers in these second-tier groups have received sufficient training they begin to run third-tier groups offering support to those involved in pastoral care. The scheme aims at a 'multiplier' effect whereby a limited availability of professional time can benefit a large number of people receiving pastoral support or counselling. He also spoke of the exploratory group that he and his wife Joy (a Group-Analyst and Adviser in Family Education to the Diocese of London) had attended over two and a half years with two other bishops and their wives, which they had asked my wife, Prue, and myself to conduct in order that they could have direct experience of the process themselves.

To give those attending the Conference an impression of what is involved in this kind of group experience, participants divided into small groups conducted by Hewlett, Joy, Prue and myself. After several such meetings, reactions and views were reported at a final plenary session.

There was the usual sharp division between those participants who concluded that group support of this kind was necessary and desirable, and others who felt that it should not be necessary. However, even those most positive to the idea in principle were concerned about the problem of how to go about finding suitably qualified professionals to help in the task.

The need is for experienced people with knowledge of, and ability to impart, basic principles of counselling and family dynamics, together with skills in leading training/support groups of this kind. I have offered to help the Dean of Windsor to compile a list of professionals with suitable experience who might be interested to participate in similar work in their area. Any Bishop who wished to develop pastoral training and support could find out from the Dean those who might be available locally, and would be able to approach them directly and negotiate, if necessary, with their employing authorities.

I should perhaps add that in the London Diocese scheme the work has been made possible through secondment for a few hours each week of NHS or Social Services staff, or it has been on a voluntary basis. It has not been a requirement that the professionals should be members of the Church of England, but a basic sympathy with the purpose of religious teachings generally is obviously desirable.

Those interested should write to the Right Reverend Michael Mann, Dean of Windsor, St George's House, Windsor Castle, Windsor, Berkshire. 